\title{
Study on the Seismic Behavior of Nuclear Pipes by Using FEM
}

\author{
Feng LIU ${ }^{1}$, Xia-Jie LIU ${ }^{1}$, Kun-Feng LI ${ }^{1}$, Yong-Hong LV${ }^{1}$, Zheng KANG ${ }^{1}$ and \\ Shi-Qing HUANG ${ }^{2}$, a
}

${ }^{1}$ China Nuclear Power Technology Research Institute, Shenzhen 518124, China

${ }^{2}$ MOE Key Lab of Disaster Forecast and Control in Engineering, Jinan University, Guangzhou 510632, China

Keywords: Nuclear pipes, Seismic behavior, FEM, Modal analysis, Spectral analysis.

\begin{abstract}
The modal analysis and spectral analysis of nuclear pipes are carried out by FEM software ANSYS. Taking the piping system of Ningde Nuclear Plant as an example, the calculation results by using software ANSYS are compared with those by using software SYSPIPE.
\end{abstract}

\section{Introduction}

In the nuclear power industry, the role of nuclear piping systems is quite significant. Bearer security in its structural design has been the focus of attention of the industry, amid seismic design is essential. In normal circumstances, seismic design of nuclear piping adopts French SYSPIPF software [1], which although is developed specifically for pipeline computing software but it is inconvenient for modeling without intuitive analysis results. Especially for complex piping line, the modeling costs too much time. And as the current internationally accepted large-scale finite element software, ANSYS has the function of seismic piping calculation. The modeling of the pipe structures is directly parameterized by APDL language, providing convenience for modifying modeling and post-processing. Work efficiency has been greatly improved resulting in design time shortened. This paper adopts ANSYS to introduce the method of seismic piping calculation and compares the calculated result with that figured out with French professional piping design software SYSPIPE.

\section{Seismic Design Method for ANSYS Piping}

Generally speaking, seismic design of piping system is the same as that of other structures by using ANSYS software. However, when involved in piping models, it is necessary to use special programming command language in ANSYS, instead of the common method based on the points, lines, surfaces or volume. The seismic calculation is usually divided into the following steps:

\section{Definition of Element Types and Material Properties.}

In ANSYS modeling piping, straight pipes commonly adopt the unit of pipe16, bended pipes adopt the unit of pipe18, and with ET instructions to define the element types. Materials mainly involve in the density of the structure, the elastic modulus and Poisson's ratio. Take accounts into damping effect, and thermal expansion coefficient and damping are also in need of consideration. The material properties adopt MP instructions to define.

\section{Modeling of the Piping Systems.}

Due to the special nature of the piping model, we only need to define the outer diameter and thickness of the piping section: (1) Use PSPEC to define data and material properties of the piping cross-sectional distribution. (2)Use POPT defining analysis criteria, ANSYS only owning two standards, one is ANSI B31.1, and the other is ASME Section III NC. (3) Adopt BRANCH to define the starting point of piping, RUN to define the extension of piping (straight pipes), BEND to define bending pipes, TEE to define T-type pipes, VAL to define valves whose quality is focused on the nodes with the unit of pipe 16 adopted for the straight pipes and bending pipes adopting the unit of pipe 18. 


\section{Loading and Constraints.}

According to the structure of the pipeline constraints in the actual position, exert constraints onto the nodes. D instruction is enough to use; load mainly refers to dead load, temperature, internal pressure and seismic loads.

ACEL instruction is applied to the acceleration of gravity; PTEMP instruction is applied to temperature loads, PPRES instruction is for internal pressure; while SED instruction is applied to response spectrum analysis.

\section{Modal Analysis.}

Modeling analysis must be carried out before analyzing anti-seismic piping. By analyzing modeling, frequency and vibration modes of the structure can be acquired. ANTYPE can be used to define the analysis type as modeling analysis.

\section{Spectral Analysis and the Results of Post-progress.}

On the basis of the modal analysis, spectral analysis is carried out. ANTYPE can be defined the type of analysis as spectral analysis. Spectrum Analysis has two main categories: single-point and multi-point spectrum analysis. Response of the structure under the earthquake can be acquired with the results of post-treatment. Furthermore, inspection and evaluation can be carried out based on the response results.

\section{Calculation of Examples}

Take some piping of Ningde Nuclear Plant as calculation model with stainless steel piping material Z2CN1810 (elastic modulus 191.5GPa, Poisson's ratio of 0.3 , thermal expansion coefficient $1.64 \times 10-3 /{ }^{\circ} \mathrm{C}$, the density of $\left.7.85 \times 103 \mathrm{~kg} / \mathrm{m} 3\right)$. The outer diameter is $323.9 \mathrm{~mm}$, the wall thickness is $4.57 \mathrm{~mm}$ and the seismic level is Grade1I. The pipeline bears the dead load, internal pressure, thermal expansion, and seismic load. When the dead load is calculated, taking the gravitational acceleration is $9.8 \mathrm{~m} / \mathrm{s} 2$, the program calculates the effect of gravity based on the piping unit linear density and mass centralization. Design pressure of $1 \mathrm{MPa}$, the operating pressure of $0.9 \mathrm{MPa}$, pipeline design temperature $100^{\circ} \mathrm{C}$. The program calculates the expansion displacement and expansion stress based on the thermal expansion coefficient of the pipe. Seismic Response modal response spectrum method for solving using modal combination method to obtain various degrees of freedom of the maximum response of the structure, determined by the response of the structure element stress, the combination method SRSS.

\section{Calculation by ANSYS.}

By the method in above Section and with the actual parameters, pipeline finite element model is established and as shown in Figure 1-2, based on which modal analysis is carried out and Table 2 covering four condition analysis,

Table 1. The natural frequency of first 10 orders from ANSYS pipeline calculation.

\begin{tabular}{|l|l|l|l|l|l|}
\hline ith Order & 1 & 2 & 3 & 4 & 5 \\
\hline frequency & 11.897 & 15.208 & 15.412 & 19.022 & 19.682 \\
\hline ith Order & 6 & 7 & 8 & 9 & 10 \\
\hline frequency & 21.788 & 23.234 & 24.431 & 25.166 & 25.415 \\
\hline
\end{tabular}




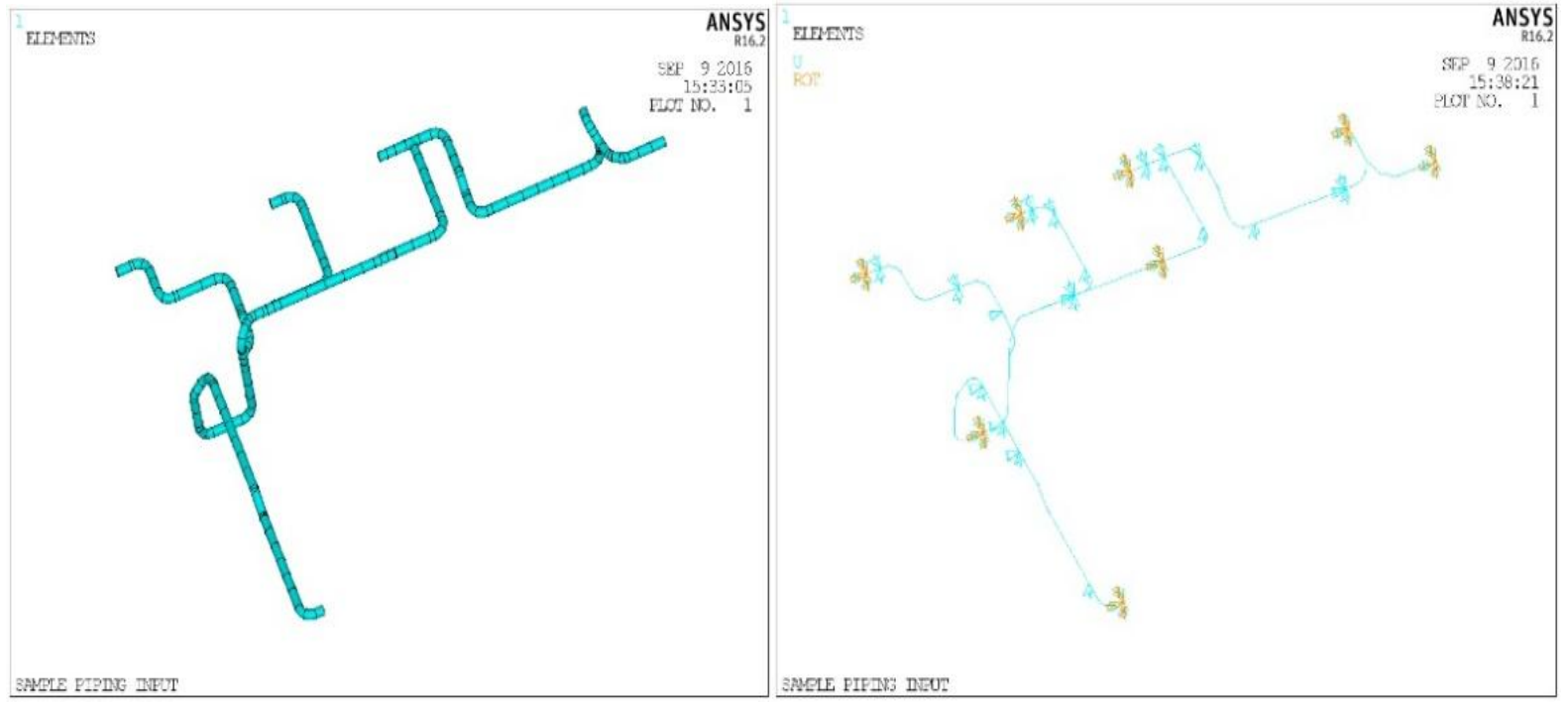

Figure 1. Pipeline finite element model.

Figure 2. Boundary constraints.

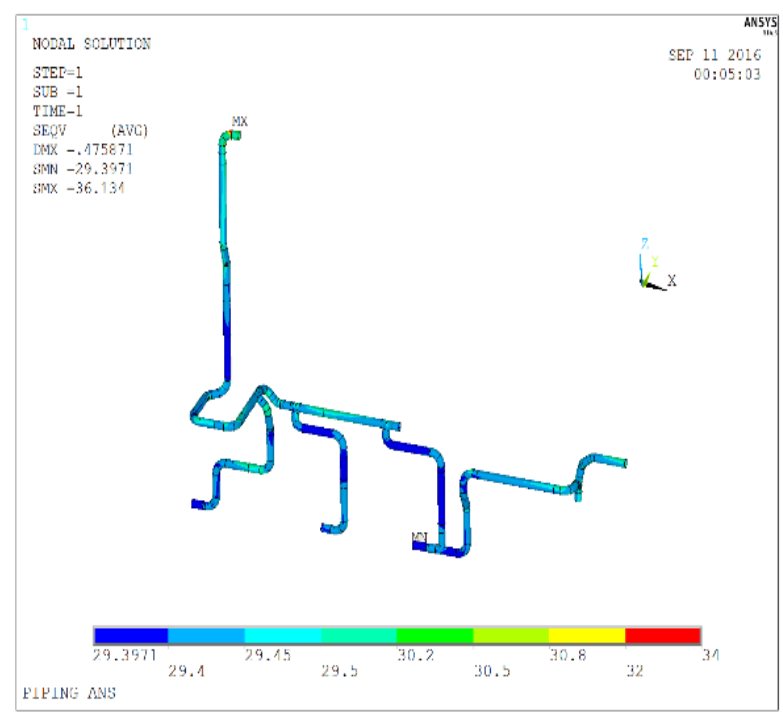

(a) O level conditions

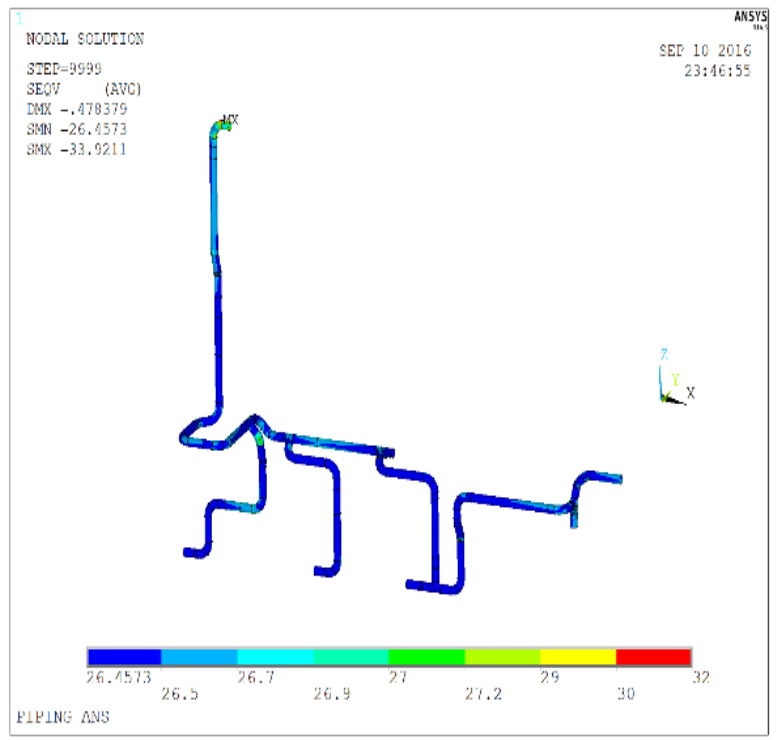

(c) B level condition

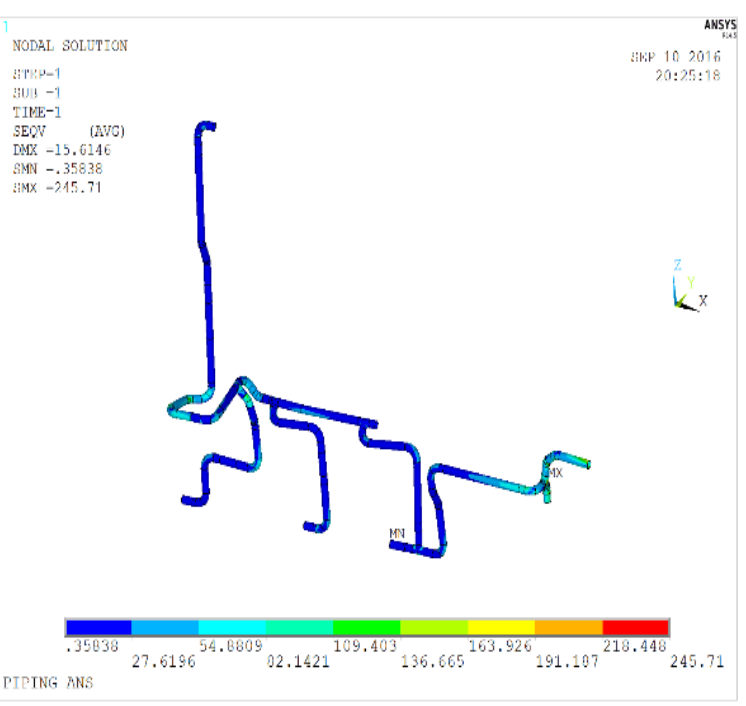

(b) A level condition.

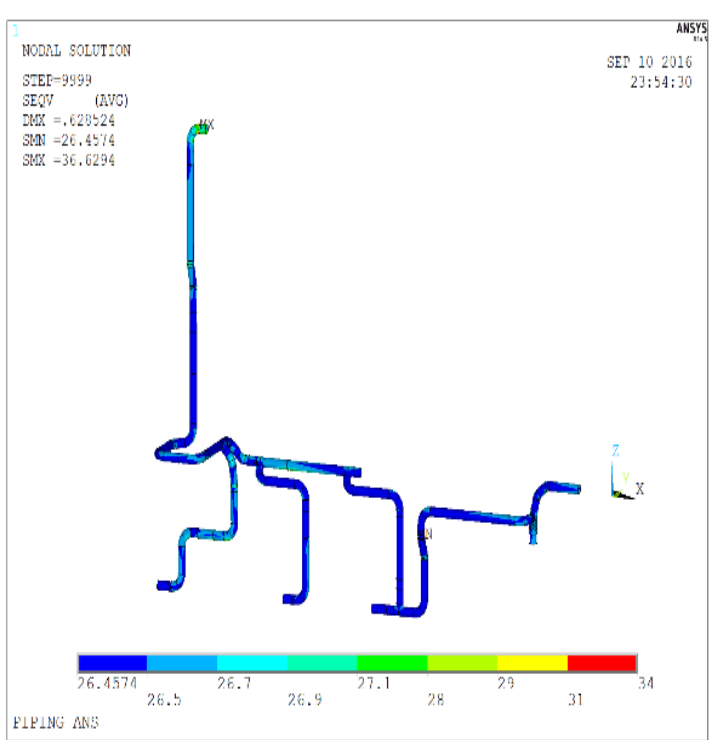

(d) C\&D level conditions.

Figure 3. Piping stress distribution. 
According to RCC-M specification requirements, various working conditions are combined into two nuclear piping stress assessment criteria and as shown in Table 2.

Table 2. RCC-M assessment guidelines. [3-4]

\begin{tabular}{|l|l|l|l|l|}
\hline Conditions & Load & $\begin{array}{l}\text { Code } \\
\text { Level }\end{array}$ & $\begin{array}{l}\text { Evaluation } \\
\text { equation }\end{array}$ & $\begin{array}{l}\text { Allowable } \\
\text { limit }\end{array}$ \\
\hline Design Conditions & Design pressure, dead load & O & $(1)$ & SH \\
\hline Normal Run & Thermal expansion & A & $(2)$ & SA \\
\hline Disturbance Run & Dead load, maximum pressure, OBE & B & $(4)$ & $1.2 \mathrm{SH}$ \\
\hline $\begin{array}{l}\text { Accident } \\
\text { Conditions }\end{array}$ & $\begin{array}{l}\text { SSELoad, Dead load, maximum } \\
\text { pressure }\end{array}$ & D & $(4)$ & $2.4 \mathrm{SH}$ \\
\hline
\end{tabular}

Table 3. Inspection and Approval of Stress for Various Conditions.

\begin{tabular}{|l|l|l|l|l|}
\hline Condition Type & $\begin{array}{l}\text { Code } \\
\text { Level }\end{array}$ & $\begin{array}{l}\text { Calculate Stress } \\
(\mathrm{MPa})\end{array}$ & $\begin{array}{l}\text { Allowable stress limits } \\
\mathrm{MPa})\end{array}$ & $\begin{array}{l}\text { Stress } \\
\text { Ratio }\end{array}$ \\
\hline Design Condition & $\mathrm{O}$ & 36.134 & 108 & 0.33 \\
\hline Normal Conditions & $\mathrm{A}$ & 245.71 & 162 & 1.52 \\
\hline Normal Conditions & $\mathrm{A}$ & 241.52 & 270 & 0.89 \\
\hline $\begin{array}{l}\text { Disturbance } \\
\text { Conditions }\end{array}$ & $\mathrm{B}$ & 33.921 & 129.6 & 0.26 \\
\hline $\begin{array}{l}\text { Emergency } \\
\text { Conditions }\end{array}$ & $\mathrm{C}$ & 36.629 & 194.4 & 0.19 \\
\hline $\begin{array}{l}\text { Accidental } \\
\text { Conditions }\end{array}$ & $\mathrm{D}$ & 36.629 & 159.2 & 0.23 \\
\hline
\end{tabular}

Nuclear pipes are assessed according to PWR nuclear islands Design rules for mechanical RCCMC3652 is O level, A level, grade B, C and D levels guidelines stress the need to satisfy the following formula.

$$
\begin{gathered}
S_{S l}=\frac{P D_{0}}{4 t_{n}}+0.75 i \frac{M_{A}}{Z} \leq S_{h} \\
S_{E}=i \frac{M_{C}}{Z} \leq S_{A} \\
S_{T E}=\frac{P D_{0}}{4 t_{n}}+0.75 i \frac{M_{A}}{Z}+i \frac{M_{C}}{Z} \leq S_{h}+S_{A} \\
S_{a}=\frac{P D_{0}}{4 t_{n}}+0.75 i \frac{M_{A}}{Z}+0.75 i \frac{M_{B}}{Z} \leq k S_{h}
\end{gathered}
$$

In which, each parameter in the RCC-M specification are defined as follows: $\mathrm{P}$ design pressure; D0 is the outer diameter of the pipe; tn is the nominal wall thickness; MA permanent load caused by closing moment; MB load generated by occasional moments together; torque range Mc thermal expansion or fixed displacement produced; $\mathrm{Z}$ pipeline carrying surface modulus; $\mathrm{i}$ is the stress intensification factor $0.75 \mathrm{i} \geq 1$; Sh basic promise of the design temperature of the material stress; SA allowable thermal expansion stress variation range; $\mathrm{k}$ is the allowable stress factor, class $\mathrm{B}$ criteria take 1.2, C-level guidelines take 1.8, D-level guidelines take 2.4. However, due to internal ANSYS program without the above evaluation equation, first via a torque by ANSYS piping unit input under load, and then using RCC-M Specification C3652 formula (1), the formula (2), the formula (3), (4) pipe stress analysis is evaluated. Each condition evaluation results are shown below. 
Table 4. Ansys calculation results to check stress according to the formula

\begin{tabular}{|l|l|l|l|l|l|l|}
\hline Condition Type & $\begin{array}{l}\text { Code } \\
\text { Level }\end{array}$ & $\begin{array}{l}\text { Evaluation } \\
\text { Formula }\end{array}$ & $\begin{array}{l}\text { Point on } \\
\text { modeling } \\
\text { nodes }\end{array}$ & $\begin{array}{l}\text { Calculated } \\
\text { Stress } \\
\text { (MPa) }\end{array}$ & $\begin{array}{l}\text { Allowable } \\
\text { stress } \\
\text { limits(MPa) }\end{array}$ & $\begin{array}{l}\text { Stress } \\
\text { Ratio }\end{array}$ \\
\hline Design Conditions & $\mathrm{O}$ & 1 & 189 & 26.32 & 108 & 0.24 \\
\hline Normal Conditions & $\mathrm{A}$ & 2 & 35 & 223.27 & 162 & 1.38 \\
\hline Normal Conditions & $\mathrm{A}$ & 3 & 35 & 241.52 & 270 & 0.89 \\
\hline $\begin{array}{l}\text { Disturbance } \\
\text { Conditions }\end{array}$ & $\mathrm{B}$ & 4 & 189 & 24.92 & 129.6 & 0.19 \\
\hline Emergency Conditions & $\mathrm{C}$ & 4 & 189 & 27.11 & 194.4 & 0.14 \\
\hline Accidental Conditions & $\mathrm{D}$ & 4 & 189 & 27.11 & 159.2 & 0.17 \\
\hline
\end{tabular}

\section{Calculation by SYSPIPE.}

By the analogous method, the modal analysis is carried with the frequency shown in Table 5. Under six conditions, the extraction stress results are shown in Table. 6.

Table 5. The natural frequency of first 10 orders from SYSPIPE piping calculation.

\begin{tabular}{|l|l|l|l|l|l|}
\hline ith Order & 1 & 2 & 3 & 4 & 5 \\
\hline Frequency & 11.248 & 13.939 & 15.316 & 18.051 & 19.427 \\
\hline ith Order & 6 & 7 & 8 & 9 & 10 \\
\hline Frequency & 19.640 & 21.040 & 22.483 & 23.401 & 25.985 \\
\hline
\end{tabular}

Table 6. SYSPIPE proofread the result of stress according to the formula.

\begin{tabular}{|l|l|l|l|l|l|l|}
\hline Condition Type & $\begin{array}{l}\text { Code } \\
\text { Level }\end{array}$ & $\begin{array}{l}\text { Evaluation } \\
\text { Formula }\end{array}$ & $\begin{array}{l}\text { Point on } \\
\text { modeling } \\
\text { nodes }\end{array}$ & $\begin{array}{l}\text { Calculation } \\
\text { Ability } \\
\text { (MPa) }\end{array}$ & $\begin{array}{l}\text { Allowable } \\
\text { stress limits } \\
\text { (MPa) }\end{array}$ & $\begin{array}{l}\text { Stress } \\
\text { Ratio }\end{array}$ \\
\hline Design Conditions & $\mathrm{O}$ & 1 & 189 & 35.06 & 108 & 0.32 \\
\hline Normal Conditions & $\mathrm{A}$ & 2 & 35 & 208.68 & 162 & 1.29 \\
\hline Normal Conditions & $\mathrm{A}$ & 3 & 35 & 234.52 & 270 & 0.87 \\
\hline $\begin{array}{l}\text { Disturbance } \\
\text { Conditions }\end{array}$ & $\mathrm{B}$ & 4 & 189 & 87.74 & 129.6 & 0.68 \\
\hline $\begin{array}{l}\text { Emergency } \\
\text { Conditions }\end{array}$ & $\mathrm{C}$ & 4 & 189 & 148.18 & 194.4 & 0.76 \\
\hline $\begin{array}{l}\text { Accidental } \\
\text { Conditions }\end{array}$ & $\mathrm{D}$ & 4 & 189 & 148.18 & 159.2 & 0.93 \\
\hline
\end{tabular}

\section{Conclusion}

This paper studies the application of ANSYS in seismic nuclear grade piping and described the method of ANSYS in anti-seismic nuclear grade piping. And take some nuclear grade piping of Ningde as a practical example to analyze the response of the piping in dead load, pressure, thermal expansion response under earthquake loads. Based on the calculation results, we can reach the result that ANSYS software and SYSPIPE software can get the same calculation results that can be verified mutually. Compared with SYSPIPE, ANSYS modeling is more convenient with more intuitive analysis results. The dangerous points can be easily found out, thus ANSYS can be used to analyze the stress of nuclear grade piping. 


\section{Acknowledgements}

The support of this work from the National Natural Science Foundation of China (Grant No. 10902043 and 11032005), the Fundamental Research Funds for the Central Universities (Grant No. 21612204), Program for New Century Excellent Talents in University (Grant No. NCET-11-0854) is acknowledged.

\section{References}

[1] Framatome, SYSPIPE 234D user's Manual [S], (2005).

[2] Ningde Nuclear Power Plant First Phase, No.3 and No.4 Unit Nuclear Island Plant Floor Response Spectra ABYNIX10001DCJG42GN A version, (2015).

[3] RCC-M PWR nuclear island mechanical equipment design and construction rules, edition 2000 $+(2002)$ Addition.

[4] GB50267-1997, Code for seismic design of nuclear power plants, (1997). 